\title{
Assessing wall stresses in bicuspid aortic valve-associated aortopathy: Forecasting the perfect storm?
}

\author{
Alex J. Barker, PhD, ${ }^{\text {a }}$ Michael Markl, PhD,,${ }^{\mathrm{a}, \mathrm{b}}$ and Paul W. M. Fedak, MD, \\ From the ${ }^{\mathrm{a}}$ Department of Radiology, Feinberg School of Medicine, and ${ }^{\mathrm{b}}$ Department of Biomedical Engineering, \\ McCormick School of Engineering, Northwestern University, Chicago, Ill; ${ }^{c}$ Division of Cardiac Surgery, \\ Bluhm Cardiovascular Institute, Northwestern Memorial Hospital, Chicago, Ill; and ${ }^{\mathrm{d}}$ Department of Cardiac \\ Sciences, Libin Cardiovascular Institute of Alberta, University of Calgary, Calgary, Alberta, Canada. \\ Disclosures: Authors have nothing to disclose with regard to commercial support. \\ Received for publication March 20, 2018; accepted for publication March 23, 2018; available ahead of print April \\ $14,2018$. \\ Address for reprints: Paul W. M. Fedak, MD, PhD, FRCSC, Department of Cardiac Sciences, Libin Cardiovas- \\ cular Institute of Alberta, University of Calgary, Rm 880, 1403-29 St, NW, Calgary, Alberta, Canada T2N \\ 2T9 (E-mail: paul.fedak@gmail.com). \\ J Thorac Cardiovasc Surg 2018;156:471-2 \\ $0022-5223 / \$ 36.00$ \\ Copyright (C) 2018 by The American Association for Thoracic Surgery \\ https://doi.org/10.1016/j.jtcvs.2018.03.092
}

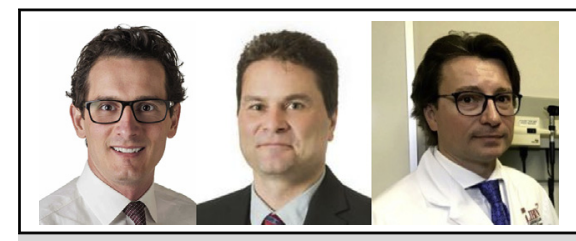

Alex J. Barker, PhD, Michael Markl, PhD, and Paul W. M. Fedak, MD, PhD, FRCSC

\section{Central Message}

The colocation of abnormal WSS regions with high wall stress may create perfect storm conditions by exposing already weakened aortic regions to high wall stress that leads to wall failure.

See Article page 492.
Prophylactic aortic resection is recommended when the ascending aorta reaches specific size thresholds. ${ }^{1}$ When deciding to resect an aorta with bicuspid valve disease, surgeons remain challenged by the so-called size paradox - the arterial wall can fail at smaller aortic sizes than the recommended guidelines for resection. ${ }^{2,3}$ Aortic rupture or dissection occurs when blood pressure-induced forces (stress) exceed the biomechanical strength of the aortic wall. Emerging research has focused on 2 important biomechanical concepts that may drive aortic wall integrity and ultimate failure of the aorta: wall stress and wall shear stress (WSS). Despite similar names, these 2 metrics are very different biomechanical stressors that influence aortopathy for different reasons. In comparison to wall stress, WSS is a measure of the frictional force caused by blood flowing along the vessel wall and is expressed at orders of magnitude lower than wall stresses. Nonetheless, via mechanotransduction and signaling pathways, WSS alters vessel wall extracellular matrix integrity and biomechanical strength. ${ }^{4}$ For example, elevated WSS is associated with altered matrix protein concentration and elastic fiber degeneration in the ascending aorta of patients with a bicuspid aortic valve (BAV). ${ }^{5}$ In contrast, wall stress represents the internal forces imposed on the aortic wall, which will fail when wall stress exceeds the regional biomechanical strength. ${ }^{6}$

Xuan and colleagues ${ }^{7}$ investigated regional wall stress in patient-specific models of ascending aortic aneurysms to understand whether a predisposition for wall failure exists in BAV. They hypothesize that wall stress will predict vessel wall rupture or dissection. Indeed, the models found that patients with BAV were exposed to higher wall stresses than patients with a tricuspid aortic valve, and these stresses were more pronounced at the sinotubular junction. Moreover, wall stresses were poorly correlated to diameter in patients with BAV, further suggesting that diameter alone may not adequately predict rupture. These important patient-specific results support the use of personalized risk stratification. However, additional due diligence with more sophisticated models is necessary. For example, as Xuan and colleagues ${ }^{7}$

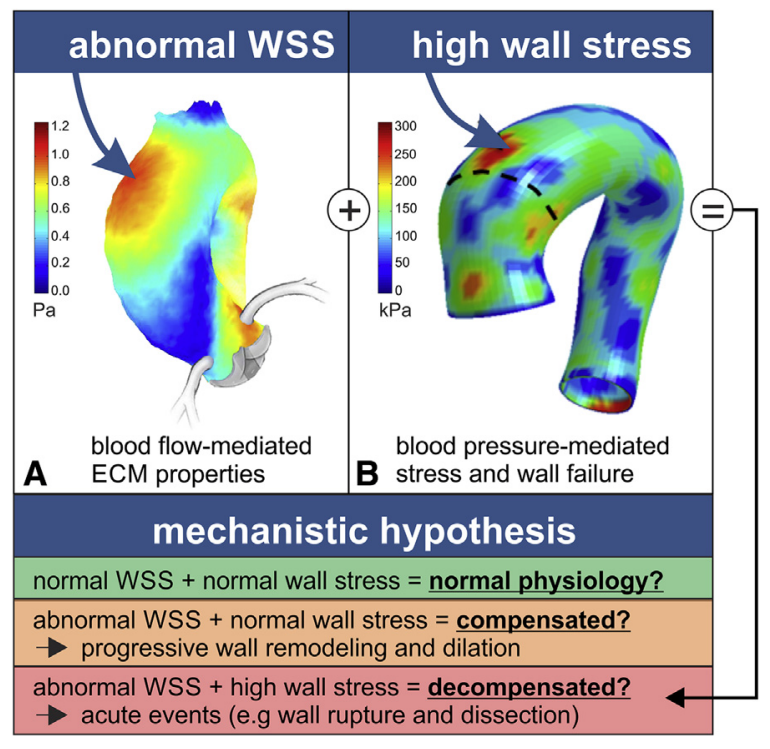

FIGURE 1. A, Mechanistic hypothesis for wall shear stress (WSS)-mediated regional vessel remodeling. ${ }^{9} \mathrm{~B}$, Mechanistic hypothesis for stressmediated regional failure. The co-location of abnormal WSS regions with high wall stress may create perfect storm conditions by exposing already weakened aortic regions to high wall stress that leads to wall failure. 
rightly point out, their model does not account for heterogeneous regional vessel properties (eg, architecture, wall strength, and wall thickness), which are known to occur in patients with $\mathrm{BAV}^{5,8}$ Admittedly, it is difficult to predict mechanical properties noninvasively and no correlation with the tissue itself was found in their study.

The findings of the study prompt one to speculate whether the combination of the 2 biomechanical concepts; that is, regional biologic dysfunction driven by WSS-mediated mechanotransduction (Figure 1, A) and regionally variable biomechanical stresses (Figure 1, B), implies that it may be possible to predict the perfect storm of impaired vessel wall biomechanics. Patients exposed to regionally abnormal WSS over time may have accelerated vessel wall degeneration, which may be co-localized with a region exposed to high wall stress (resulting in rupture or dissection). The possibility of predicting abnormal vessel wall properties that align with high wall stresses may forecast the beginnings of a perfect storm capable of catastrophic damage.

\section{References}

1. Nishimura RA, Otto CM, Bonow RO, Caravello BA, Erwin JP III, Guyton RA, et al. 2014 AHA/ACC Guideline for the management of patients with valvular heart disease: a report of the American College of Cardiology/American Heart Association task force on practice guidelines. Circulation. 2014;129:e521-643.

2. Elefteriades JA, Ziganshin BA, Rizzo JA, Fang H, Tranquilli M, Paruchur V, et al. Indications and imaging for aortic surgery: size and other matters. J Thorac Cardiovasc Surg. 2015;149(2 Suppl):S10-3.

3. Pape LA, Tsai TT, Isselbacher EM, Pape LA, Patel HJ, Froehlich JB, et al. Aortic diameter of $5.5 \mathrm{~cm}$ or greater is not a good predictor of type A aortic dissection: observations from the International Registry of Acute Aortic Dissection (IRAD). Circulation. 2007;116:1120-7.

4. Lehoux S, Tedgui A. Cellular mechanics and gene expression in blood vessels. $J$ Biomech. 2003;36:631-43.

5. Guzzardi DG, Barker AJ, van Ooij P, Malaisrie SC, Puthumana JJ, Belke DD, et al. Valve-related hemodynamics mediate human bicuspid aortopathy: insights from wall shear stress mapping. J Am Coll Cardiol. 2015; 66:892-900.

6. Pasta S, Rinaudo A, Luca A, Pilato M, Scardulla C, Gleason TG, et al. Difference in hemodynamic and wall stress of ascending thoracic aortic aneurysms with bicuspid and tricuspid aortic valve. J Biomech. 2013;46:1729-38.

7. Xuan Y, Wang Z, Liu R, Haraldsson H, Hope MD, Saloner DA, et al. Wall stress on ascending thoracic aortic aneurysms with bicuspid compared with tricuspid aortic valve. J Thorac Cardiovasc Surg. 2018;156:492-500.

8. Tsamis A, Phillippi JA, Koch RG, Chan PG, Krawiec JT, D’Amore A, et al. Extracellular matrix fiber microarchitecture is region-specific in bicuspid aortic valveassociated ascending aortopathy. J Thorac Cardiovasc Surg. 2016;151: 1718-28.e1715.

9. van Ooij P, Markl M, Collins JD, Carr JC, Rigsby C, Bonow RO, et al. Aortic valve stenosis alters expression of regional aortic wall shear stress: new insights from a 4-dimensional flow magnetic resonance imaging study of 571 subjects. J Am Heart Assoc. 2017;6:e05959. 